\title{
Patient characteristics associated with false arrhythmia alarms in intensive care
}

\author{
This article was published in the following Dove Press journal: \\ Therapeutics and Clinical Risk Management \\ 19 April 2017 \\ Number of times this article has been viewed
}

\author{
Patricia R Harris ${ }^{1,2}$ \\ Jessica K Zègre-Hemsey ${ }^{3,4}$ \\ Daniel Schindler ${ }^{5}$ \\ Yong Bai ${ }^{6}$ \\ Michele M Pelter ${ }^{2,7}$ \\ Xiao $\mathrm{Hu}^{2,8}$ \\ 'Department of Nursing, School \\ of Health and Natural Sciences, \\ Dominican University of California, \\ San Rafael, ${ }^{2}$ Department of \\ Physiological Nursing, School of \\ Nursing, University of California, \\ San Francisco, CA, ${ }^{3}$ School of Nursing, \\ ${ }^{4}$ Department of Emergency Medicine, \\ School of Medicine, University \\ of North Carolina at Chapel Hill, \\ NC, ${ }^{5}$ Intensive Care Unit, The \\ Neuroscience Center, Sutter Eden \\ Medical Center, Castro Valley, ${ }^{6} \mathrm{Hu}$ \\ Research Laboratory, Department \\ of Physiological Nursing, School of \\ Nursing, University of California, \\ San Francisco, ${ }^{7}$ ECG Monitoring \\ Research Lab, Department of \\ Physiological Nursing, School of \\ Nursing, ${ }^{8}$ Physiological Nursing \\ and Neurological Surgery, Affiliate \\ Faculty of Institute for Computational \\ Health Sciences Core Faculty UCB/ \\ UCSF Joint Bio-Engineering Graduate \\ Program, University of California, \\ San Francisco, CA, USA
}

Correspondence: Patricia R Harris Dominican University of California, School of Health and Natural Sciences, Department of Nursing, 50 Acacia Avenue, San Rafael, CA 9490I, USA Tel + I 4I54583797

Email patricia.harris@dominican.edu
Introduction: A high rate of false arrhythmia alarms in the intensive care unit (ICU) leads to alarm fatigue, the condition of desensitization and potentially inappropriate silencing of alarms due to frequent invalid and nonactionable alarms, often referred to as false alarms.

Objective: The aim of this study was to identify patient characteristics, such as gender, age, body mass index, and diagnosis associated with frequent false arrhythmia alarms in the ICU. Methods: This descriptive, observational study prospectively enrolled patients who were consecutively admitted to one of five adult ICUs ( 77 beds) at an urban medical center over a period of 31 days in 2013. All monitor alarms and continuous waveforms were stored on a secure server. Nurse scientists with expertise in cardiac monitoring used a standardized protocol to annotate six clinically important types of arrhythmia alarms (asystole, pause, ventricular fibrillation, ventricular tachycardia, accelerated ventricular rhythm, and ventricular bradycardia) as true or false. Total monitoring time for each patient was measured, and the number of false alarms per hour was calculated for these six alarm types. Medical records were examined to acquire data on patient characteristics.

Results: A total of 461 unique patients (mean age $=60 \pm 17$ years) were enrolled, generating a total of 2,558,760 alarms, including all levels of arrhythmia, parameter, and technical alarms. There were 48,404 hours of patient monitoring time, and an average overall alarm rate of 52 alarms/ hour. Investigators annotated 12,671 arrhythmia alarms; 11,345 (89.5\%) were determined to be false. Two hundred and fifty patients (54\%) generated at least one of the six annotated alarm types. Two patients generated 6,940 arrhythmia alarms (55\%). The number of false alarms per monitored hour for patients' annotated arrhythmia alarms ranged from 0.0 to 7.7, and the duration of these false alarms per hour ranged from 0.0 to 158.8 seconds. Patient characteristics were compared in relation to 1) the number and 2) the duration of false arrhythmia alarms per 24-hour period, using nonparametric statistics to minimize the influence of outliers. Among the significant associations were the following: age $\geq 60$ years $(P=0.013 ; P=0.034)$, confused mental status ( $P<0.001$ for both comparisons), cardiovascular diagnoses $(P<0.001$ for both comparisons), electrocardiographic (ECG) features, such as wide ECG waveforms that correspond to ventricular depolarization known as QRS complex due to bundle branch block (BBB) $(P=0.003 ; P=0.004)$ or ventricular paced rhythm ( $P=0.002$ for both comparisons), respiratory diagnoses $(P=0.004$ for both comparisons), and support with mechanical ventilation, including those with primary diagnoses other than respiratory ones ( $P<0.001$ for both comparisons).

Conclusion: Patients likely to trigger a higher number of false arrhythmia alarms may be those with older age, confusion, cardiovascular diagnoses, and ECG features that indicate BBB or ventricular pacing, respiratory diagnoses, and mechanical ventilatory support. Algorithm improvements could focus on better noise reduction (eg, motion artifact with confused state) and distinguishing BBB and paced rhythms from ventricular arrhythmias. Increasing awareness of patient conditions that apparently trigger a higher rate of false arrhythmia alarms may be useful for reducing unnecessary noise and improving alarm management.

Keywords: alarm fatigue, electrocardiography, patient safety submit your manuscript Dovepress f in 10
Therapeutics and Clinical Risk Management 2017:13 499-513

499

(c) (7) () 2017 Harris et al. This work is published and licensed by Dove Medical Press Limited. The full terms of this license are available at https://www.dovepress.com/terms.php cc) hereby accept the Terms. Non-commercial uses of the work are permitted without any further permission from Dove Medical Press Limited, provided the work is properly attributed. For permission for commercial use of this work, please see paragraphs 4.2 and 5 of our Terms (https://www.dovepress.com/terms.php). 


\section{Introduction}

In health care, alarm fatigue refers to sensory overload, occurring when clinical personnel are exposed to an excessive number of alarms. This phenomenon can result in desensitization and missed alarms ${ }^{1}$ and can potentially create a serious safety issue, especially for patients in a critical care environment. Research has shown that physiological monitor alarms often are invalid, ${ }^{2}$ exacerbating the problem. The Joint Commission (TJC) on accreditation of hospitals and health care organizations has identified alarm management as an essential National Patient Safety Goal. ${ }^{3}$

Physiological monitoring in the intensive care unit (ICU) aims to provide health care personnel with up-to-date, accurate information on patients' minute-by-minute changes. ${ }^{46}$ The alarm systems are designed to quickly alert practitioners to abnormal patient conditions and are considered highly sensitive in recognizing true acute problems. However, this accuracy is offset by frequent false alarms, ie, alarms that are triggered but do not alert health care personnel to true problems.

This situation is not new and is not isolated to health care. In 1984, Breznitz, 7 a researcher in psychology, argued that to be effective, a warning system must be trustworthy. He described the rise of early warning systems throughout the 20th century and noted that with an increase in alarm sensitivity, providing more accurate and immediate identification of true problems, there was a corresponding decrease in alarm specificity, resulting in an increase in inaccurate alarms for situations that were not problematic. Breznitz ${ }^{7}$ maintained that the effectiveness of a warning system depends upon its credibility, and credibility is decreased with every false alarm.

Further research in psychology has shown that during tasks, which demand a high level of mental attention, there may be limits to the capacity for conscious recognition of additional stimuli. The term inattention blindness was coined as a result of experiments showing that participants, directed to engage in specific mental tasks, could inadvertently overlook events taking place in the center of their visual fields. ${ }^{8}$ Subsequent studies by MacDonald and Lavie ${ }^{9}$ demonstrated the existence of a comparable phenomenon related to hearing, termed inattention deafness.

The field of aviation has been vigilant in addressing the concern of auditory deafness in relation to alarm fatigue. ${ }^{10}$ Giraudet et a ${ }^{11}$ recently investigated the failure of personnel to react to auditory alarms in the cockpit. These researchers demonstrated that changes in participants' electroencephalograms, recorded during simulated flight with high-demand tasks, such as airplane landing, might be associated with interference in auditory perception.
Researchers are engaged in applying these findings to the excess of alarms and sensory overload in health care. $\mathrm{TJC}^{12}$ and the US Federal Food and Drug Administration (FDA) ${ }^{13}$ reports show that excessive alarms have a negative effect on patient safety. Suggestions for improvement include the following: institutional standards for alarm management; ${ }^{14}$ development of algorithms to include multiple parameters for improving alarm specificity; ${ }^{15-19}$ systematic assessment of alarm parameter settings with appropriate adjustments, according to individual patient needs, ${ }^{1,2,14,20}$ regular reevaluation of each patient's need for continuous monitoring; ${ }^{1}$ and clarification of the clinician's experience in using physiologic monitoring technology. ${ }^{21}$ While studies have focused on the overall prevalence and impact of numerous physiological alarms, research to date has provided little guidance to increase understanding of patient characteristics associated with frequent false alarms. This study aims to fill the gap.

\section{Aim}

The primary aim of this research was to determine patient characteristics associated with frequent false arrhythmia alarms in the ICU.

A variety of patient factors, including demographics and clinical characteristics, were assessed in relation to the frequency and duration of false arrhythmia alarms.

\section{Methods}

Investigators at a large urban medical center and university teaching hospital conducted a prospective, observational study designed to collect all waveform data from 77 physiological monitors (Solar 8000i, software version 5.4; GE Healthcare, Milwaukee, WI, USA) associated with beds in five adult ICUs over a 31-day period. ${ }^{2}$ One of the specific aims of our study was to determine patient characteristics associated with a high rate of false alarms. Characteristics postulated to affect signal quality and potentially associated with frequent nonactionable, or invalid, alarms were examined closely for this analysis. The complete study methods have been previously described. ${ }^{2}$

\section{Ethical oversight}

The Committee on Human Research of the University of California - San Francisco Human Research Protection Program (the university's internal review board) approved the study with a waiver of written informed consent from all subjects. A waiver of written informed consent was deemed acceptable because the research involved no more than minimal risk, the waiver would not adversely affect the rights and welfare of the participants, the research could not practicably 
be carried out without the waiver; and whenever appropriate, the participants would be provided with additional pertinent information after participation.

\section{Enrollment}

Data were collected from the monitors of all patients consecutively admitted to one of five ICUs (one coronary care, two medical-surgical, and two neurosurgical units) during the mentioned 31-day period in 2013. Secure data transfer, allowing alarms, monitor parameter settings, numeric digital displays, as well as electrocardiographic (ECG), invasive pressure, pulse oximetry, and respiratory waveforms, was provided by a research version CareScape Gateway (GE Healthcare). The waveform data extraction did not influence patient care.

All patients were assigned a numerical study identifier to ensure maintenance of patient privacy.

\section{Assessment of all alarms}

Patients were monitored using four limb leads and one precordial lead, as part of the routine care in the ICU. With the assistance of medical center bioengineers, a secure, state-of-the-art server (BedMasterEx, Excel Medical, Jupiter, FL, USA) was installed to extract and store the continuous waveform and alarm data obtained, including up to seven ECG waveforms from each bedside monitor. The researchers' display could be adjusted to view up to seven ECG leads as well as pressure, pulse oximetry, or respiratory waveform data. Patient identifiers were removed, and the waveform and alarm data were coded. Excel Medical provided printed versions of the waveforms, termed alarm reports, which included all seven ECG leads and associated waveforms. The reports also identified all digital information that was displayed on the monitor at the time an alarm was triggered and included information about the duration of each alarm, audio (on/off), alarm level (crisis, warning, advisory, or message), pacemaker mode (on/off), and parameter settings. While alarms set at the message level only provided a flashing visual display and were inaudible, researchers reasoned that message alarms could still require attention and potentially contribute to the burden of sensory overload. Therefore, both audible and inaudible alarms were included in the overall alarm assessment. The waveform and alarm data were not used for clinical decision making.

All alarms captured over the 1-month period were arranged into three categories: arrhythmia (ie, alarms associated with abnormal cardiac rhythms); parameter (ie, alarms associated with physiological signs falling outside of set boundaries, such as high versus low heart rate, respiratory rate, or blood pressure); and technical (ie, alarms associated with equipment problems, such as low battery). Given the potential for both inattention blindness and inattention deafness - referring to the problem of a health care worker, for instance, who is so engaged in a targeted mental activity that he or she inadvertently overlooks critical visual or auditory information ${ }^{8,9}-$ we determined to count all alarms that occurred during the month for the calculation of alarm burden, the average number of alarms per patient's bed per day.

\section{Measurement of monitoring time}

Patients' monitoring times were distinguished by visually examining ECG signals, as well as by a computer algorithm developed by one of the investigators (YB) to identify the presence of a patient on the monitor. Alarms that were triggered without an identified patient attached to the monitor were eliminated from the arrhythmia analysis but were included in the overall compilation of alarms.

\section{Assessment of patient characteristics associated with false alarms}

The electronic medical record was reviewed, and patient information was obtained after the waveform data were collected, using a standardized data extraction tool. Only deidentified data were entered into a secure database (MediData Rave, New York, NY, USA).

Patient characteristics were recorded and assessed in relation to the frequency and duration of false arrhythmia alarms. These characteristics included patient demographics, such as age, race, ethnicity, and gender, as well as clinical characteristics, such as body mass index (BMI), cognitive state (confusion or agitation), presence of tremor, and tobacco-smoking status (potential agitation due to nicotine withdrawal). Supportive treatments, such as mechanical ventilation, pacemakers, and ventricular assist devices, used during the ICU stay, also were compared in relation to the frequency and duration of alarms. Patients who experienced bundle branch block (BBB) during ECG monitoring were identified. Finally, the patients' main medical diagnoses at time of ICU discharge (up to three diagnoses for each patient) were examined.

\section{Analysis of arrhythmia alarms}

Nurse scientists with training and expertise in ECG monitoring examined waveforms surrounding arrhythmia alarms associated with six clinically important conditions:

- Accelerated ventricular: $\geq 6$ consecutive ventricular beats between 50 and 100 beats per minute (bpm)

- Asystole: no QRS detected for 5-6 seconds

- Pause: 3-second interval without a QRS complex

- Ventricular bradycardia: $\geq 3$ consecutive ventricular beats at rate $\leq 50 \mathrm{bpm}$. 
- Ventricular fibrillation: coarse flutter waves without QRS complexes

- Ventricular tachycardia: $\geq 6$ consecutive ventricular beats with rate $\geq 100 \mathrm{bpm}$.

The hospital default setting was at the crisis level for asystole, ventricular fibrillation, and ventricular tachycardia alarms (three loud beeps and flashing visual alert). The default setting was at the warning level for accelerated ventricular, pause, and ventricular bradycardia alarms (two loud beeps and flashing visual alert). The investigators used the alarm reports as references to aid annotation. Alarms were annotated as true, false, or indeterminate using a standardized protocol. ${ }^{2}$

The annotators, including the primary investigator, met regularly to compare assessments of physiological waveforms and signal quality. In addition, a sample of annotated alarms was randomly selected for annotation by more than one investigator to assess interrater reliability.

\section{Statistical analysis}

Statistical analyses were performed using SPSS statistics, version 23 (IBM, Armonk, NY, USA). Number and duration of alarms per patient per hour, and per day, were calculated according to the number of monitored hours for each patient.

\section{Nonparametric tests}

For comparisons of groups without normal distributions, nonparametric statistics were used to minimize the influence of outliers. Alpha was set at 0.005 .

\section{Regression analyses}

Using a binary variable to separate those who generated false arrhythmia alarms from those who did not, univariate and multivariate binary logistic regression analyses were performed to identify the patient characteristics associated with false arrhythmia alarms. To further examine the distribution of data and the strength of relationships between variables, bootstrap analysis with 1,000 replications was performed when appropriate for the statistical method. For the univariate regression analyses, alpha was set at 0.10 to ensure identification of appropriate variables to be included in the multivariate regression analysis. Alpha was set at 0.05 for the multivariate regression.

\section{Code Blue events}

The frequency of arrhythmia alarms in association with cardiopulmonary arrests resulting in Code Blue events was explored, the rationale being that cardiac arrest is a medical diagnosis and deterioration of a patient's condition may be associated with frequent alarms. Data were collected to examine whether or not clinically important cardiopulmonary events correctly triggered arrhythmia alarms. Arrhythmia alarms over a period of 1 minute prior to and during the event were assessed for appropriateness, ie, true alarms reflecting critical conditions.

\section{Signal quality}

The annotators determined the signal quality of the waveforms through visual inspection and rating on a three-point scale of good, fair, or poor quality. Good referred to clearly visible waveforms in all available leads, fair referred to waveforms with moderate baseline wander or moderate noise, but with clear QRS complexes, and poor quality referred to waveforms that did not allow definitive analysis of the rhythm.

\section{Results}

Over the 1-month period, a total of 461 unique patients were enrolled.

\section{Number of alarms}

There were a total of 2,558,760 alarms, separated into the three categories, arrhythmia, parameter, and technical, as reported previously. ${ }^{2}$ The total number of alarms included was as follows:

- Arrhythmia alarms: 1,051,054

- Parameter alarms: 612,927

- Technical alarms: 791,632.

The number of audible alarms within all three categories equaled 381,560 .

\section{Patient monitoring time}

There were 48,173 hours of patient-monitoring data, ranging from 5 hours and 20 minutes to 744 hours ( 24 hours per day for 31 days). The median monitoring time was 52.9 hours. The combined units' daily census averaged 66 occupied beds per day.

Alarms with the audio on generated an average audible alarm burden of 187 audible alarms per bed per day. ${ }^{2}$

\section{Patient demographics}

Patient demographics reflect the typical characteristics of the San Francisco Bay area and are presented in Table 1.

The number of patients admitted to each unit is provided in Table 2. 
Table I Patient demographics

\begin{tabular}{|c|c|c|c|c|}
\hline Characteristics & $\begin{array}{l}\text { All study patients } \\
\mathbf{N}(\%)\end{array}$ & $\begin{array}{l}\text { Patients with } \geq \mathbf{I} \text { false } \\
\text { arrhythmia alarms } \mathbf{N}(\%)\end{array}$ & $\begin{array}{l}\text { Patients with only true } \\
\text { arrhythmia alarms N (\%) }\end{array}$ & $\begin{array}{l}\text { Patients with no } \\
\text { arrhythmia alarms N (\%) }\end{array}$ \\
\hline Number of patients, $\mathrm{N}$ & 461 & 238 & 12 & 211 \\
\hline Mean age, years & $60 \pm 17$ & $61 \pm 17$ & $68 \pm 13$ & $57 \pm 17$ \\
\hline \multicolumn{5}{|l|}{ Gender } \\
\hline Male & $250(54.2)$ & $122(5 \mid .3)$ & $7(58.3)$ & $|2|(57.3)$ \\
\hline \multicolumn{5}{|l|}{ Race } \\
\hline African American & $35(7.6)$ & $21(8.8)$ & I (8.3) & $13(6.2)$ \\
\hline Asian & $76(16.5)$ & $4 I(17.2)$ & $2(16.7)$ & $33(15.6)$ \\
\hline Caucasian & $281(61.0)$ & $143(60.1)$ & $7(58.3)$ & $131(62.1)$ \\
\hline $\begin{array}{l}\text { Other race, or } \\
\text { decline to state }\end{array}$ & $69(15.0)$ & $33(13.9)$ & $2(16.7)$ & $34(16.1)$ \\
\hline \multicolumn{5}{|l|}{ Ethnicity } \\
\hline Hispanic & $5 I(I I)$ & $31(13.0)$ & I (8.3) & $19(9.0)$ \\
\hline
\end{tabular}

Note: Mean \pm standard deviation.

Patients often had more than one discharge diagnosis. The investigators recorded the top three diagnoses, as primary diagnoses, if applicable. Patients' primary discharge diagnoses are outlined in Table 3.

\section{False arrhythmia alarms}

Out of the 461 patients (51.8\%), 250 patients generated at least one of the six annotated alarm types during the 1-month period. The nurse scientists annotated a total of six arrhythmia alarms for this analysis. Interrater reliability was measured at $95 \%$ (Cohen's kappa score $=0.86$ ).

After systematic examination and vetting of the 12,671 annotated alarms, 11,345 were deemed false (89.5\%) and $1,326(10.5 \%)$ were deemed true.

Alarms annotated as false were attributed to 238 of the 250 ICU patients (95.2\%). Twelve patients generated only true alarms. In other words, 238 of the 461 patients (51.6\%) admitted to the ICU during the 1-month period generated at least one false arrhythmia alarm, which by default would have been set at crisis or warning level. Of all the arrhythmia alarms annotated, 15 were designated as indeterminate $(0.1 \%)$ by the investigators. The number of false alarms per hour and per day for each patient was calculated, as well as the duration (in seconds) of false alarms per hour and per day.
For all patients who received physiological monitoring in the ICU and generated at least one of the annotated arrhythmia alarms, whether true or false $(n=238)$, the median number of false arrhythmia alarms was greater than one per patient over a 24-hour period. The range was 0-184 false alarms over 24 hours. The data indicated that only a few patients generated frequent false alarms (refer "Patients with frequent alarms" subsection and Figure 1 for more details).

The median duration of false arrhythmia alarms was approximately 7.5 seconds per patient over a 24 -hour period. The range was 0-63.5 minutes over a 24 -hour period. The data indicated that only a few patients generated longduration false alarms (Figure 2).

\section{Unit of admission}

Patients' unit of admission was significantly associated with the total number and duration of false alarms over a 24-hour period of patient monitoring time. In this analysis, the coronary care unit generated the highest number and longest duration of alarms. Detailed results using nonparametric tests of the type of ICU in relation to the number or duration of alarms are provided in Table 4.

While the medical-surgical unit had the greatest raw number of total alarms - due to the alarms generated by two patients - over the 1-month period (reported in column

Table 2 Unit of admission

\begin{tabular}{lllll}
\hline $\begin{array}{l}\text { Intensive care unit } \\
\text { (initial admission) }\end{array}$ & $\begin{array}{l}\text { All study } \\
\text { patients N, \% }\end{array}$ & $\begin{array}{l}\text { Patients with } \geq \text { I false } \\
\text { arrhythmia alarms N, \% }\end{array}$ & $\begin{array}{l}\text { Patients with only true } \\
\text { arrhythmia alarms N, \% }\end{array}$ & $\begin{array}{l}\text { Patients with no } \\
\text { arrhythmia alarms N, \% }\end{array}$ \\
\hline Neurological & $197(42.70)$ & $90(19.52)$ & $3(0.65)$ & $104(22.56)$ \\
Coronary & $83(18.00)$ & $5 I(I 1.06)$ & $5(1.08)$ & $27(5.86)$ \\
Medical-surgical & $18 I(39.30)$ & $97(21.04)$ & $4(0.87)$ & $80(17.35)$ \\
\hline
\end{tabular}

Note: $\mathrm{N}=46$. 
Table 3 Patient discharge diagnoses ${ }^{\mathrm{a}}$

\begin{tabular}{ll}
\hline Body system category & $\begin{array}{l}\text { Number of patients with diagnosis in } \\
\text { category (\% of patients with the diagnosis) }\end{array}$ \\
\hline Cardiac (arrhythmia, heart failure, myocardial infarction, other cardiac diagnoses) & $123(26.7)$ \\
Endocrine (adrenal, pancreatic including diabetes mellitus, thyroid) & $33(7.2)$ \\
Gastrointestinal (including gastrointestinal bleeding, other gastrointestinal disorders) & $30(6.5)$ \\
Hepatic & $37(8.0)$ \\
Musculoskeletal & $30(6.5)$ \\
Neurological (stroke, seizure, subarachnoid hemorrhage, other neurological diagnoses) & $208(45.1)$ \\
Renal (acute kidney injury, other renal diagnoses) & $44(9.5)$ \\
Respiratory (pneumonia, acute respiratory distress syndrome, other respiratory diagnoses) & $119(25.8)$ \\
Multiple organ (multiple organ dysfunction syndrome, sepsis, trauma) & $45(9.8)$ \\
Other diagnoses (substance withdrawal, other uncategorized diagnoses) & $52(11.3)$ \\
Total diagnoses & 721 \\
\hline
\end{tabular}

Notes: $\mathrm{N}=46 \mathrm{I}$; ap to three top diagnoses may be listed for one patient, so number of diagnoses is greater than number of patients enrolled in study.

2 ), the number and duration of false arrhythmia alarms per 24 hours of patient monitoring time were greatest in the coronary care unit.

The association of type of unit with the total number and total duration of alarms over a 24-hour period is represented in Figure 3.

\section{Results of nonparmetric analyses Demographics}

Age $\geq 60$ years (range: $19-96$ years) showed a statistically significant association with high number and long duration of alarms. The alarm data were highly skewed, with only a few patients generating most of the alarms, so nonparametric tests were used to minimize the influence of outliers (Table 5).

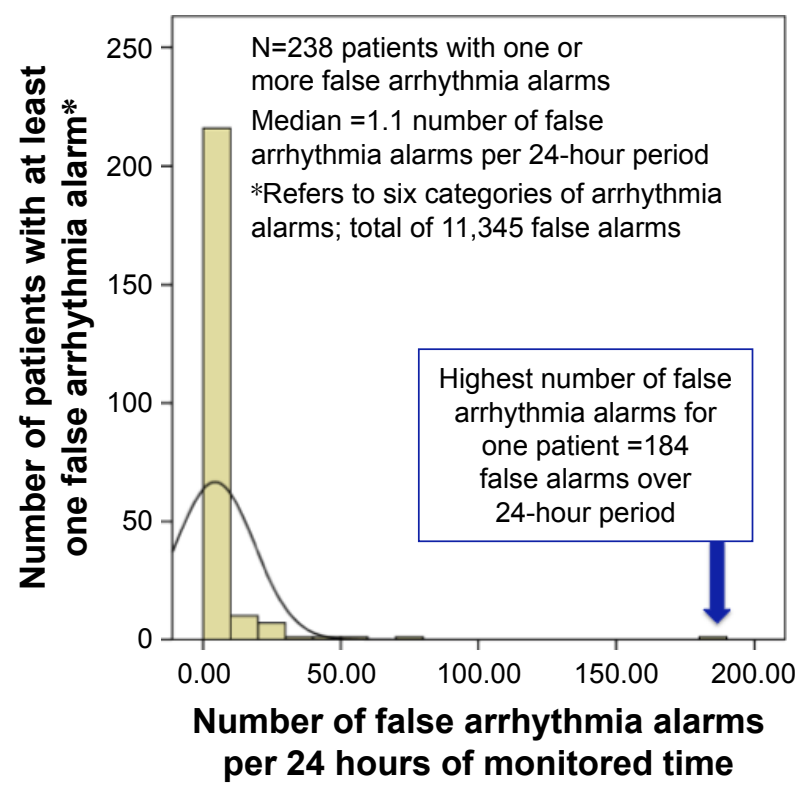

Figure I Number of false arrhythmia alarms per 24 hours.
Findings associated with patients' clinical features

Altered mental status, specifically confusion and agitation, also was associated with a higher number and longer duration of false arrhythmia alarms.

However, older age and altered mental status were weakly correlated (Cramer's V $=0.143, P=0.002$ ). The odds ratio for patients aged $\geq 60$ years to experience confusion or agitation was 2/1 (confidence interval: 1.3-3.0, Pearson Chi-square, $P=0.002$ ).

An ECG feature associated with significantly more frequent false alarms and longer duration of false alarms was wide QRS complex due to either left or right BBB (Table 6).

Over a 24-hour period, patients with BBB generated a significant number of false ventricular arrhythmia alarms, in particular. Frequent accelerated ventricular alarms

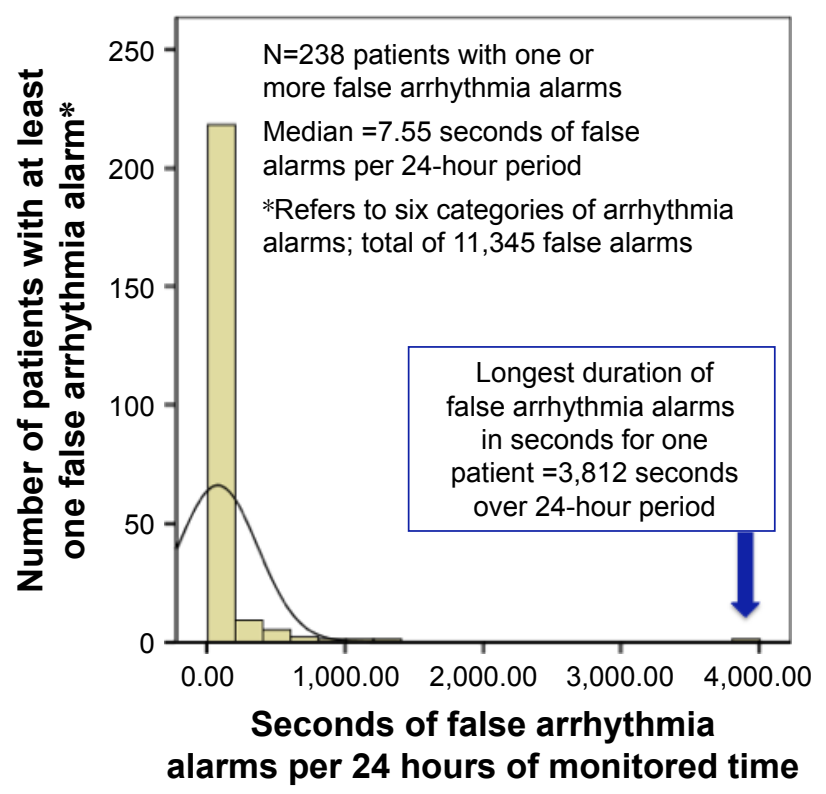

Figure 2 Duration of false arrhythmia alarms per 24 hours in the intensive care unit. 
Table 4 Patients' intensive care unit of admission in relation to frequency and duration of false arrhythmia alarms

\begin{tabular}{|c|c|c|c|c|c|c|c|c|}
\hline \multirow[t]{2}{*}{$\begin{array}{l}\text { Unit of admission, } \\
n=46 \mathrm{I}\end{array}$} & \multirow{2}{*}{$\begin{array}{l}\text { Total number of } \\
\text { false arrhythmia } \\
\text { alarms over } \\
\text { I-month study } \\
\text { period (\% of sum) }\end{array}$} & \multicolumn{2}{|c|}{$\begin{array}{l}\text { Number of false } \\
\text { arrhythmia alarms } \\
\text { per } 24 \text { hours of } \\
\text { monitored time }\end{array}$} & \multirow[t]{2}{*}{$P$-value } & \multirow{2}{*}{$\begin{array}{l}\text { Total duration in } \\
\text { seconds of false } \\
\text { arrhythmia alarms } \\
\text { over I-month study } \\
\text { period (\% of duration) }\end{array}$} & \multicolumn{2}{|c|}{$\begin{array}{l}\text { Duration in seconds } \\
\text { of false arrhythmia } \\
\text { alarms per } 24 \text { hours } \\
\text { of monitored time }\end{array}$} & \multirow[t]{2}{*}{$P$-value } \\
\hline & & Median & Range (sum) & & & Median & Range (sum) & \\
\hline Coronary, $n=83$ & $2,576(22.7)$ & 0.6 & $0-5$ I (374) & $0.00 I^{a}$ & $48,792(36.0)$ & 5.9 & $0-3,812(9,623)$ & $<0.00 \mathrm{I}^{\mathrm{b}}$ \\
\hline Medical-surgical, $n=|8|$ & $7,861(69.3)$ & 0.2 & $0-184(495)$ & & $74,846(55.2)$ & 0.5 & $0-I, 228(6,042)$ & \\
\hline Neurologic, $n=197$ & $908(8.0)$ & 0.0 & $0-134(3 \mid 3)$ & & II,839 (8.7) & 0.0 & $0-2,263(4,379)$ & \\
\hline Total, $\mathbf{N}=46$ I & 11,345 & 0.1 & $0-184(I,|8|)$ & & 135,477 & 0.4 & $0-3,812(20,044)$ & \\
\hline
\end{tabular}

Notes: Kruskal-Wallis test, a nonparametric test, minimizes the effect of outliers. alndicates alarms per 24 hours were significantly higher in coronary care unit compared to other units; bindicates duration of alarms per 24 hours significantly higher in coronary care unit compared to other units. Bold figures depict statistically significant results with $P<0.05$.

showed the strongest effect size, according to the MannWhitney $U$-test, the mean rank for patients with BBB also was significantly higher compared to that for patients without BBB.

\section{Cardiac devices and ECG features}

We examined each alarm type to identify patients who had a medical device that had potential for mimicking the wide QRS of ventricular arrhythmias, such as a ventricular pacemaker or ventricular assist device (VAD), to identify the possibility that these patients were prone to having more frequent and longer duration of false ventricular arrhythmia alarms.

Patients with ventricular paced rhythms had significantly higher number and duration of false alarms per 24-hour period. In addition, cardiac rhythms associated with VADs also were significantly associated with higher number and duration of false alarms per 24-hour period (Table 7).
For patients with pacemakers, false accelerated ventricular alarms were frequently triggered and showed the greatest difference for median numbers per 24 hours and duration of alarms per 24 hours.

\section{Mechanical ventilation}

There were 167 patients who received mechanical ventilation for a minimum of 2 hours during their ICU stay. Mechanical ventilation intervention was significantly associated with more frequent and longer duration of false arrhythmia alarms overall (Table 7).

In the category of number of alarms per hour, the median number of alarms per hour was significantly greater for the group of patients undergoing mechanical ventilation compared to the group that did not receive mechanical ventilation. The range was much greater for mechanically ventilated patients ie, 0-3,225 alarms per hour for those with mechanical ventilation, and 0-108 for those without ventilatory support.
A

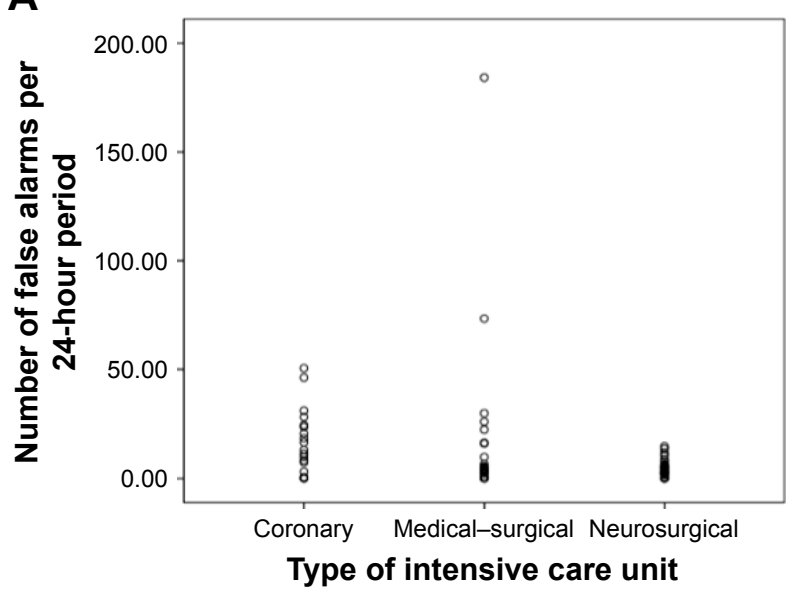

B

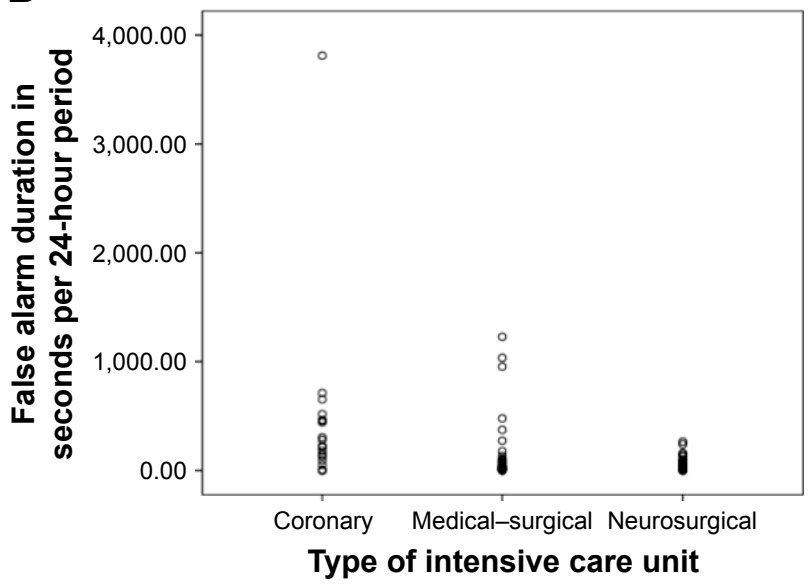

Figure 3 (A) Number and (B) duration of false alarms per hour according to type of intensive care unit. 
Table 5 Patient demographics in relation to frequent false arrhythmia alarms

\begin{tabular}{|c|c|c|c|c|}
\hline \multirow{2}{*}{$\begin{array}{l}\text { Patient } \\
\text { demographic } \\
\text { characteristic }\end{array}$} & \multicolumn{2}{|c|}{$\begin{array}{l}\text { Number of false arrhythmia alarms } \\
\text { per } 24 \text { monitored hours }\end{array}$} & \multicolumn{2}{|c|}{$\begin{array}{l}\text { Duration in seconds of false arrhythmia } \\
\text { alarms per } 24 \text { monitored hours }\end{array}$} \\
\hline & Median (range) & $P$-value & Median (range) & $P$-value \\
\hline Age, $>60$ years & & 0.013 & & 0.034 \\
\hline$\leq 60, \mathrm{n}=230$ & $0.0(0-5 \mathrm{I})$ & & $0.0(0-3,8 \mid 2)$ & \\
\hline$>60, n=231$ & $0.3(0-184)$ & & I. $0(0-2,263)$ & \\
\hline Gender & & 0.126 & & 0.201 \\
\hline Male, $n=250$ & $0.0(0-73)$ & & $0.0(0-3,8 \mid 2)$ & \\
\hline Female, $n=2 I I$ & $0.3(0-184)$ & & $0.9(0-2,263)$ & \\
\hline${ }^{\#}$ Ethnicity & & 0.788 & & 0.547 \\
\hline Hispanic, $n=5$ I & $0.2(0-11)$ & & $0.6(0-3,8 \mid 2)$ & \\
\hline Non-Hispanic, $n=400$ & $0.2(0-184)$ & & $0.5(0-2,263)$ & \\
\hline Racial categories & & 0.161 & & 0.154 \\
\hline Asian, $\mathrm{n}=35$ & $0.2(0-184)$ & & $1.0(0-1,326)$ & \\
\hline Black, $n=76$ & $0.2(0-5 \mathrm{I})$ & & $1.0(0-275)$ & \\
\hline White, $n=28$ I & $0.1(0-134)$ & & $0.4(0-2,263)$ & \\
\hline Other, $n=69$ & $0.0(0-8)$ & & $0.0(0-3,8 \mid 2)$ & \\
\hline
\end{tabular}

Notes: Nonparametric tests: Mann-Whitney $U$ or Kruskal-Wallis. Number and duration of false arrhythmia alarms per hour compared between patients who do or do not have the selected characteristic $(\mathrm{N}=46 \mathrm{I})$; ${ }^{\#}$ ten patients declined to state ethnicity; the data was treated as missing, and excluded from the calculation. Bold figures depict statistically significant results with $P<0.05$.

The Mann-Whitney $U$-test indicated a small-to-medium effect size.

The Mann-Whitney $U$-test also indicated a small-tomedium effect size for duration of these alarms. The difference in the time duration for false accelerated ventricular alarms between those receiving assisted ventilation and those who did not ranged from zero to 14,600 seconds for those receiving mechanical ventilation and from zero to 345 seconds for those without ventilatory support.

Close examination revealed that accelerated ventricular alarms helped drive the effect size in the mechanically ventilated group, similar to the findings for patients with

Table 6 Patient characteristics, including distinct electrocardiographic features, in relation to frequent false arrhythmia alarms

\begin{tabular}{|c|c|c|c|c|}
\hline \multirow{2}{*}{$\begin{array}{l}\text { Patient clinical characteristics } \\
\text { Clinical or electrocardiographic } \\
\text { characteristic }\end{array}$} & \multicolumn{2}{|c|}{$\begin{array}{l}\text { Higher number of false arrhythmia } \\
\text { alarms per monitored hour }\end{array}$} & \multicolumn{2}{|c|}{$\begin{array}{l}\text { Longer duration in seconds of false } \\
\text { arrhythmia alarms per monitored hour }\end{array}$} \\
\hline & Median (range; sum) & $P$-value & Median (range; sum) & $P$-value \\
\hline \multicolumn{2}{|c|}{ Altered mental status (confusion or agitation documented) } & $<0.001$ & & $<0.001$ \\
\hline Confused, $\mathrm{n}=198$ & $0.5(0-184 ; 800)$ & & $2.0(0-2,263 ; 10,505)$ & \\
\hline Not confused, $n=263$ & $0.0(0-5 I ; 38 I)$ & & $0.0(0-3,8 \mid 2 ; 9,538)$ & \\
\hline$\wedge \wedge$ Body mass index & & 0.794 & & 0.456 \\
\hline Body mass index $\geq 30, n=142$ & $0.2(0-51 ; 300)$ & & $0.5(0-3,8 \mid 2 ; 7,939)$ & \\
\hline Body mass index $<30, n=3 \mid 4$ & $0.7(0-184 ; 870)$ & & $0.0(0-2,263 ; 11,759)$ & \\
\hline Current smoker & & 0.327 & & 0.516 \\
\hline Smoker, $\mathrm{n}=7 \mathrm{I}$ & $0.0(0-5|;| 44)$ & & $0.0(0-3,8|2 ; 5,58|)$ & \\
\hline Nonsmoker, $\mathrm{n}=390$ & $0.2(0-184 ; 1,037)$ & & $0.5(0-2,263 ; 14,463)$ & \\
\hline Seizures documented & & 0.614 & & 0.769 \\
\hline Seizures, $n=19$ & $0.2(0-8 ; 30)$ & & $0.7(0-184 ; 1,|5|)$ & \\
\hline No seizures, $n=442$ & $0.1(0-184 ; 1,151)$ & & $0.3(0-3,812 ; 19,883)$ & \\
\hline Tremors documented & & 0.901 & & 0.746 \\
\hline Tremors, $\mathrm{n}=36$ & $0.0(0-26 ; 90)$ & & $0.0(0-954 ; 1,408)$ & \\
\hline No tremors, $n=425$ & $0.1(0-|84 ; 1,09|)$ & & $0.4(0-3,8 \mid 2 ; 18,653)$ & \\
\hline BBB per cardiac monitor & & 0.003 & & 0.004 \\
\hline $\mathrm{BBB}, \mathrm{n}=4 \mathrm{I}$ & $0.6(0-184 ; 339)$ & & $4.0(0-3,8|2 ; 8| 9 \mid)$, & \\
\hline No $B B B, n=420$ & $0.0(0-134 ; 842)$ & & $0.0(0-2,263 ;$ I I,852) & \\
\hline
\end{tabular}

Notes: Mann-Whitney U-test: number and duration of false arrhythmia alarms per hour compared between patients who do or do not have the selected characteristic $(\mathrm{N}=46 \mathrm{l})$; ^^five patients had no recorded weight. Missing data was excluded from the calculation. Results in bold are statistically significant with alpha set at 0.05 , patients with a characteristic depicted in bold have significantly more arrhythmia alarms than those patients without the characteristic.

Abbreviation: BBB, Bundle branch block. 
Table 7 Medical interventions and diagnoses in relation to frequent false arrhythmia alarms

\begin{tabular}{|c|c|c|c|c|}
\hline \multirow{2}{*}{$\begin{array}{l}\text { Patient characteristics } \\
\text { Cardiac interventions } \\
\text { (associated with } \\
\text { electrocardiographic changes) }\end{array}$} & \multicolumn{2}{|c|}{$\begin{array}{l}\text { Higher number of false arrhythmia } \\
\text { alarms per monitored hour }\end{array}$} & \multicolumn{2}{|c|}{$\begin{array}{l}\text { Longer duration in seconds of false } \\
\text { arrhythmia alarms per monitored hour }\end{array}$} \\
\hline & $\begin{array}{l}\text { Median } \\
\text { (range; sum) }\end{array}$ & $\begin{array}{l}\text { P-value; additional } \\
\text { statistics for } \\
\text { significant results }\end{array}$ & Median (range; sum) & $\begin{array}{l}\text { P-value; additional } \\
\text { statistics for } \\
\text { significant results }\end{array}$ \\
\hline \multicolumn{5}{|c|}{ \#Pacemaker (temporary and permanent) } \\
\hline No, $n=429$ & $0.1(0-184 ; 766)$ & $\begin{array}{l}0.002 ; U=4,559 \\
z=-3.107 ; r=0.15\end{array}$ & $0.1(0-1,228 ; 10,438)$ & $\begin{array}{l}0.002 ; U=4,589 \\
z=-3.07 I ; r=0.14\end{array}$ \\
\hline Yes, $n=3$ I & $0.9(0-5 I ; 284)$ & & $10.5(0-3,182 ; 7,113)$ & \\
\hline \multicolumn{5}{|l|}{ VAD } \\
\hline No, $n=458$ & $0.1(0-184 ; 994)$ & $\begin{array}{l}0.016 ; U=I 63 \\
z=-2.419 ; r=0.11\end{array}$ & $0.2(0-3,182 ; 16,872)$ & $\begin{array}{l}0.009 ; U=\mid 21 \\
z=-2.620 ; r=0.12\end{array}$ \\
\hline Yes, $n=3$ & II.3 (I-46; 58) & & $218.0(11-458 ; 687)$ & \\
\hline \multicolumn{5}{|l|}{ Respiratory intervention } \\
\hline \multicolumn{5}{|l|}{ MV } \\
\hline No, $n=294$ & $0.0(0-5 I ; 384)$ & $\begin{array}{l}<0.001 ; U=19,625 \\
z=-3.803 ; r=0.18\end{array}$ & $0.0(0-954 ; 4,180)$ & $\begin{array}{l}<0.001 ; U=19,298 \\
z=-4.066 ; r=0.19\end{array}$ \\
\hline Yes, $n=167$ & $0.4(0-184 ; 669)$ & & $1.2(0-3,8 \mid 2 ; 17,559)$ & \\
\hline \multicolumn{5}{|c|}{ Physiological system/medical diagnosis } \\
\hline \multicolumn{5}{|l|}{$C V$} \\
\hline No, $n=333$ & $0.0(0-46 ; 447)$ & $\begin{array}{l}<0.00 I ; U=16,724 \\
z=-3.803 ; r=0.18\end{array}$ & $0.0(0-654 ; 5,875)$ & $\begin{array}{l}<0.00 I ; U=16,884 \\
z=3.680 ; r=0.18\end{array}$ \\
\hline Yes, $n=\mid 28$ & $0.5(0-184 ; 606)$ & & $1.7(0-3,8$ I $2 ; 11,684)$ & \\
\hline \multicolumn{5}{|l|}{ Endocrine } \\
\hline No, $n=428$ & $0.1(0-73 ; 847)$ & 0.737 & $0.2(0-3,812 ; 16,152)$ & 0.883 \\
\hline Yes, $n=33$ & $0.2(0-184 ; 206)$ & & $0.4(0-1,034 ; 1,407)$ & \\
\hline \multicolumn{5}{|l|}{ GI } \\
\hline No, $n=427$ & $0.1(0-184 ; 1,016)$ & 0.400 & $0.4(0-3,8|2 ; 17,2| 4)$ & 0.295 \\
\hline Yes, $n=34$ & $0.3(0-22 ; 36)$ & & $0.0(0-177 ; 345)$ & \\
\hline \multicolumn{5}{|l|}{ Hepatic } \\
\hline No, $n=424$ & $0.2(0-184 ; 1,010)$ & 0.289 & $0.4(0-3,812 ; 17,083)$ & 0.284 \\
\hline Yes, $n=37$ & $0.0(0-22 ; 42)$ & & $0.0(0-176 ; 475)$ & \\
\hline \multicolumn{5}{|l|}{ Musculoskeletal } \\
\hline No, $n=431$ & $0.1(0-73 ; 844)$ & 0.549 & $0.2(0-1,3|2 ;| 6,32 \mid)$ & 0.702 \\
\hline Yes, $n=30$ & $0.4(0-184 ; 208)$ & & I.5 (0-I,034; I,238) & \\
\hline \multicolumn{5}{|l|}{ Neurological } \\
\hline No, $n=253$ & $0.2(0-31 ; 507)$ & 0.339 & $0.4(0-3,812 ; 10,982)$ & 0.394 \\
\hline Yes, $n=208$ & $0.0(0-184 ; 1,052)$ & & $0.0(0-1,228 ; 6,577)$ & \\
\hline \multicolumn{5}{|l|}{ Renal } \\
\hline No, $n=417$ & $0.0(0-184 ; 917)$ & 0.114 & $0.0(0-3,8|2 ;| 4,854)$ & 0.059 \\
\hline Yes, $n=44$ & $0.3(0-73 ; 136)$ & & $0.8(0-1,228 ; 2,705)$ & \\
\hline \multicolumn{5}{|c|}{ Respiratory, includes mechanical ventilation patients } \\
\hline No, $n=254$ & $0.0(0-5 I ; 358)$ & $\begin{array}{l}0.004 ; U=54,843 \\
z=-2.859 ; r=0.13\end{array}$ & $0.0(0-954 ; 3,989)$ & $\begin{array}{l}0.004 ; U=54,804 \\
z=-2.896 ; r=0.14\end{array}$ \\
\hline Yes, $n=207$ & $0.3(0-184 ; 695)$ & & $0.8(0-3,8 \mid 2 ; 13,570)$ & \\
\hline \multicolumn{5}{|l|}{ MODS } \\
\hline No, $n=4 \mid 6$ & $0.1(0-5 I ; 5 I)$ & 0.415 & $0.1(0-51 ; 728)$ & 0.273 \\
\hline Yes, $n=45$ & $0.2(0-184 ; 324)$ & & $0.8(0-1,228 ; 3,9 \mid 3)$ & \\
\hline \multicolumn{5}{|c|}{ Other diagnoses, including substance withdrawal } \\
\hline No, 409 & $0.2(0-184 ; 1,023)$ & 0.064 & $0.5(0-3,812 ; 16,897)$ & 0.095 \\
\hline Yes, $n=52$ & $0.0(0-7 ; 29)$ & & $0.0(-274 ; 662)$ & \\
\hline
\end{tabular}

Notes: Mann-Whitney U-test: number and duration of false arrhythmia alarm per hour compared between patients who do or do not have the selected characteristic $(\mathrm{N}=46 \mathrm{I})$; Results in bold are statistically significant with alpha set at 0.05 , patients with a characteristic depicted in bold have significantly more arrhythmia alarms than those patients without the characteristic. "One patient's pacemaker status was unclear, and the data was treated as missing. Missing data was excluded from the calculation.

Abbreviations: CV, cardiovascular; GI, gastrointestinal; MODS, multiple organ dysfunction syndrome; MV, mechanically ventilated; VAD, ventricular assist device. 
pacemakers or BBB. The Mann-Whitney $U$-test indicated a small-to-medium effect size for duration of accelerated ventricular alarms.

\section{Patient diagnoses}

Along with respiratory disorders, patients diagnosed with cardiac disease, including acute coronary syndrome and heart failure, experienced significantly more frequent and longer duration of false alarms compared to other patients (Table 7). Results of patient medical treatments and primary diagnoses associated with number or duration of alarms using nonparametric tests are outlined in Table 7.

\section{Univariate patient predictors associated with false arrhythmia alarms}

Logistic regression analyses were performed to more clearly distinguish individual patient variables associated with false alarms. A categorical variable was created to identify patients who generated false arrhythmia alarms and those who did not. The results showed that patients with age $\geq 60$ years, altered mental status (confusion and agitation), BBB, paced rhythm, and/or mechanical ventilation were more likely to have false arrhythmia alarms.

The three patients with ventricular assist devices were seen to make a significant contribution to false arrhythmia alarms in our nonparametric analyses. However, the $P$-value was very high, and the results were nonsensical for the regression analysis (Table 8).

\section{Multivariate patient predictors associated with false arrhythmia alarms}

After identifying the variables that were candidates for making a significant contribution to the high number of alarms, a final multivariate analysis revealed that patients who had altered mental status, BBB, and/or mechanical ventilation were most likely to generate a high number of false arrhythmia alarms.

Age $\geq 60$ years and paced rhythm did not remain significant in the multivariable model (Table 9).

\section{Code Blue events}

The number of cardiopulmonary arrests associated with Code Blue announcements recorded during the 1-month period

Table 8 Patients who experienced at least one false arrhythmia alarm during their ICU stay

\begin{tabular}{|c|c|c|c|c|c|c|}
\hline Characteristic/constant & Coefficient B & Standard error & Wald $\chi^{2}$ & $P$-value & Odds ratio & $95 \% \mathrm{Cl}$ \\
\hline Age $>60$ years & 0.339 & 0.187 & 3.289 & 0.070 & 1.40 & $0.97-2.03$ \\
\hline Constant & -0.104 & 0.132 & 0.626 & 0.429 & 0.90 & \\
\hline Gender & 0.248 & 0.187 & 1.746 & 0.186 & 1.28 & $0.89-1.85$ \\
\hline Constant & -0.048 & 0.127 & 0.144 & 0.704 & 0.95 & \\
\hline Ethnicity & 0.388 & 0.304 & 1.634 & 0.201 & 1.47 & $0.8 \mathrm{I}-2.67$ \\
\hline Constant & 0.050 & 0.100 & 0.250 & 0.617 & 1.05 & \\
\hline Race & -0.071 & 0.073 & 0.957 & 0.328 & 0.931 & $0.8 \mathrm{I}-\mathrm{I} .07$ \\
\hline Constant & 0.383 & 0.339 & 1.281 & 0.258 & 1.467 & \\
\hline $\begin{array}{l}\text { Altered mental status (confusion or } \\
\text { agitation) }\end{array}$ & 0.934 & 0.226 & 17.037 & $<0.001$ & 2.545 & $1.63-3.97$ \\
\hline Constant & -0.163 & 0.108 & 2.274 & 0.132 & 0.849 & \\
\hline Body mass index $>30$ & 0.116 & 0.203 & 0.326 & 0.536 & 1.123 & $0.76-1.67$ \\
\hline Constant & 0.025 & 0.113 & 0.051 & 0.821 & 1.026 & \\
\hline Current smoker & -0.311 & 0.259 & 1.438 & 0.231 & 0.733 & $0.44-1.22$ \\
\hline Constant & 0.113 & 0.101 & 1.240 & 0.266 & 1.120 & \\
\hline Seizures documented & 0.043 & 0.469 & 0.008 & 0.929 & 1.043 & $0.42-2.62$ \\
\hline Constant & 0.063 & 0.095 & 0.443 & 0.506 & 1.065 & \\
\hline Tremors documented & -0.101 & 0.348 & 0.303 & 0.582 & 0.826 & $0.42-1.63$ \\
\hline Constant & 0.080 & 0.097 & 0.680 & 0.410 & 1.083 & \\
\hline BBB per cardiac monitor & 0.984 & 0.367 & 7.173 & 0.007 & 2.674 & $1.30-5.49$ \\
\hline Constant & -0.014 & 0.097 & 0.021 & 0.884 & 0.986 & \\
\hline Pacemaker (temporary and permanent) & 0.638 & 0.373 & 2.917 & 0.088 & 1.892 & $0.91-3.93$ \\
\hline Constant & 0.021 & 0.096 & 0.049 & 0.825 & 1.022 & \\
\hline VAD & 21.150 & $23,205.422$ & 0.000 & 0.999 & $1.533 \mathrm{E}+9$ & ${ }^{\wedge} 0.00-$ \\
\hline Constant & 0.052 & 0.093 & 0.314 & 0.575 & $\mathrm{I} .054$ & \\
\hline MV & 0.837 & 0.200 & 17.512 & $<0.001$ & 2.309 & $1.56-3.42$ \\
\hline Constant & -0.232 & 0.117 & 3.914 & 0.048 & 0.793 & \\
\hline
\end{tabular}

Notes: Univariate binary logistic regression (alpha set at 0.010 for retention in a multivariate logistic regression); $N=461 ; 238$ patients experienced false alarms; characteristics associated with significant higher number of alarms are in bold. Lines in bold depict statistically significant results with $P<0.005$. $\wedge^{\text {indicates }}$ results in this case were uninterpretable due to low number of VAD patients.

Abbreviations: BBB, bundle branch block; Cl, confidence interval; ICU, intensive care unit; MV, mechanically ventilated; VAD, ventricular assist device. 
Table 9 Characteristics of patients who experienced at least one false arrhythmia alarm during their ICU stay

\begin{tabular}{lllllll}
\hline Characteristic/constant & Coefficient $\mathbf{B}$ & Standard error & Wald $\chi^{2}$ & P-value & Odds ratio & $\mathbf{9 5 \%}$ Cl \\
\hline Age $>60$ years & 0.133 & 0.199 & 0.450 & 0.502 & 1.143 & $0.77-1.69$ \\
Altered mental status (confusion or agitation) & $\mathbf{0 . 9 0 2}$ & $\mathbf{0 . 2 3 4}$ & $\mathbf{1 4 . 8 7 6}$ & $<\mathbf{0 . 0 0 I}$ & $\mathbf{2 . 4 6 6}$ & $\mathbf{1 . 5 6 - 3 . 9 0}$ \\
BBB per cardiac monitor & $\mathbf{0 . 8 8 5}$ & $\mathbf{0 . 3 8 3}$ & $\mathbf{5 . 3 3 5}$ & $\mathbf{0 . 0 2 I}$ & $\mathbf{2 . 4 2 4}$ & $\mathbf{I . 1 4 - 5 . 1 4}$ \\
Pacemaker (temporary and permanent) & 0.310 & 0.399 & 0.606 & 0.436 & 1.364 & $0.62-2.98$ \\
MV & $\mathbf{0 . 7 3 4}$ & $\mathbf{0 . 2 0 8}$ & $\mathbf{I 2 . 4 1 0}$ & $<\mathbf{0 . 0 0 I}$ & $\mathbf{2 . 0 8 3}$ & $\mathbf{1 . 3 9 - 3 . 1 3}$ \\
Constant & -0.576 & 0.160 & $\mathbf{1 3 . 0 2 7}$ & $<0.00 \mathrm{I}$ & 0.562 & \\
\hline
\end{tabular}

Notes: Multivariate binary logistic regression; $\mathrm{N}=46$ I; 238 patients experienced false alarms; characteristics associated with significant higher number of alarms are in bold. Lines in bold depict statistically significant results with $P<0.005$.

Abbreviations: $\mathrm{BBB}$, bundle branch block; $\mathrm{Cl}$, confidence interval; $\mathrm{ICU}$, intensive care unit; $\mathrm{MV}$, mechanically ventilated.

included 17 events, experienced by 11 unique individuals $(2.4 \%$ of total $\mathrm{N})$.

Patients who experienced a cardiopulmonary arrest associated with a Code Blue event triggered significantly more arrhythmia alarms overall on the monitor compared to those who did not experience such an event. With the exception of false asystole alarms, the patients' monitors also were significantly more likely to generate false arrhythmia alarms compared to the rest of the ICU population (Mann-Whitney $U$-test, $P \leq 0.002)$. However, these patients also were significantly more likely to trigger true alarms (Mann-Whitney $U$-test, $P=0.001$ ) (Table 10).

\section{Signal quality}

Of the alarms designated as false, $27 \%$ were rated as being of fair or poor quality. Signal quality was rated as good for $73 \%$ of the false alarms. Of the alarms designated as true, $7 \%$ were rated as fair or poor. Signal quality was rated as good for $93 \%$ of the true alarms, as reported previously. ${ }^{2}$

\section{Additional finding: patients with frequent alarms}

One patient generated 5,696 of the 11,345 false alarms $(50.2 \%)$. Most of the alarms generated by this patient were ventricular $(5,602$ out of 5,696 alarms or $98.4 \%)$, including accelerated ventricular, ventricular bradycardia, and ventricular tachycardia alarms. The patient generated an average of 7.7 alarms per hour; the mean alarm duration was 43.1 seconds per hour. Alarm noise lasted an average of 17.2 minutes per day for this patient.

A second patient generated 1,178 of the false alarms $(10.4 \%)$. All of the false alarms triggered by this patient were ventricular arrhythmias (100\%).

Between the two patients, 6,874 false arrhythmia alarms were triggered $(60.6 \%$ of all false alarms; $54.2 \%$ of all annotated alarms, including both true and false alarms). The patients had left and right BBBs and were mechanically ventilated.
Examination of patients' alarm data revealed that a total of 10 patients generated at least one alarm per monitored hour. These patients, representing $2 \%$ of the study sample, generated 8,789 alarms annotated during the study period; 8,720 ( $76.9 \%$ of false alarms) were annotated as false; $79(6.0 \%$ of true alarms) were annotated as true.

\section{Discussion}

This study builds upon our previous work ${ }^{2}$ and is the first to assess the rate and duration of invalid or nonactionable arrhythmia alarms in relation with patient characteristics.

\section{Need for alarm management}

Monitoring for arrhythmias remains an important surveillance tool to protect patients at risk; however, as our study demonstrates, the number of false alarms is staggering.

Our research reinforces the findings of a 2011 survey of hospital personnel on alarm safety practices, which reported that nonactionable alarms are frequent in critical care. ${ }^{22}$ Funk et $\mathrm{al}^{22}$ found that in most hospitals, the prevalence of false or nonactionable alarms remains a persistent problem. Thus, $75 \%$ of respondents agreed that nuisance alarms occur frequently; $71 \%$ agreed that nuisance alarms interrupt patient care; $71 \%$ stated that nuisance alarms reduce trust in the authenticity of alarms; and most disturbing, 18\% reported instances of patient harm related to alarms.

An earlier survey, conducted in $2005-06$ by Korneiwicz et al, ${ }^{23}$ reported similar findings. The researchers recommended the development of designs to promote appropriate use of equipment, increased role for clinicians to advocate for alarm management education and safety, recognition of the complexity of alarm management, and appropriate allocation of resources for development of effective management.

Our study supports the survey respondents' perceptions that frequent false, nonactionable alarms are problematic. 
Table 10 Code Blue - cardiopulmonary arrest events

\begin{tabular}{|c|c|c|c|c|}
\hline \multirow[t]{2}{*}{$\begin{array}{l}\text { Type of arrhythmia } \\
\text { alarm }\end{array}$} & \multicolumn{2}{|c|}{$\begin{array}{l}\text { False alarms triggered by patients who } \\
\text { experienced cardiopulmonary arrest }\end{array}$} & \multicolumn{2}{|c|}{$\begin{array}{l}\text { True alarms triggered by patients who } \\
\text { experienced cardiopulmonary arrest }\end{array}$} \\
\hline & $\begin{array}{l}\text { Number of alarms } \\
\text { triggered (\% of total } \\
\text { number of alarms in } \\
\text { category); mean rank }\end{array}$ & $\begin{array}{l}P \text {-value; additional } \\
\text { statistics for significant } \\
\text { results }\end{array}$ & $\begin{array}{l}\text { Number of alarms } \\
\text { triggered (\% of total } \\
\text { number of alarms in } \\
\text { category); mean rank }\end{array}$ & $\begin{array}{l}\text { P-value; additional } \\
\text { statistics for significant } \\
\text { results }\end{array}$ \\
\hline \multicolumn{5}{|l|}{ Accelerated ventricular } \\
\hline Yes & 73 (1.8\%); 356.9 & $\begin{array}{l}<0.00 I ; U=I, 090.5 \\
z=-4.628 ; r=0.22\end{array}$ & 199 (85.5\%); 304.5 & $\begin{array}{l}<0.001 ; U=I, 667.0 \\
z=-4.906 ; 0.23\end{array}$ \\
\hline No & 4,068 (98.2\%); 227.9 & & 31 (13.5\%); 229.2 & \\
\hline \multicolumn{5}{|l|}{ Asystole } \\
\hline Yes & 31 (5.8\%); 270.6 & $\begin{array}{l}0.17 I ; U=2,039.5 \\
z=-1.369 ; r=0.06\end{array}$ & 28 ( $10.6 \%) ; 325.3$ & $\begin{array}{l}<0.00 I ; U=I, 438.0 \\
z=-6.297 ; r=0.29\end{array}$ \\
\hline No & 503 (94.2\%); 230.0 & & 235 (89.4\%); 228.7 & \\
\hline \multicolumn{5}{|l|}{ Pause } \\
\hline Yes & 82 (4.2\%); 379.I & $\begin{array}{l}<0.00 I ; U=846 \\
z=-4.695 ; r=0.22\end{array}$ & 20 (9.5\%); 282.2 & $\begin{array}{l}0.00 I ; U=I, 9 I 2 ; \\
z=-3.286 ; r=0.15\end{array}$ \\
\hline No & I,893 (95.8\%); 227.4 & & 257 (90.5\%)229.8 & \\
\hline \multicolumn{5}{|l|}{ Ventricular bradycardia } \\
\hline Yes & I 8 (1.5\%); 339.4 & $\begin{array}{l}<0.00 I ; U=I, 282.5: \\
z=-6.029 ; r=0.28\end{array}$ & 9 (20.9\%); 308.4 & $\begin{array}{l}<0.00 I ; U=I, 624.0 \\
z=-6.798 ; r=0.32\end{array}$ \\
\hline No & I,204 (98.5\%); 228.4 & & 34 (79.1\%); 229.1 & \\
\hline \multicolumn{5}{|l|}{ Ventricular fibrillation } \\
\hline Yes & 4 (8.0\%); 266.3 & $\begin{array}{l}0.002 ; U=2,086.0 \\
z=-3.103 ; r=0.15\end{array}$ & 53 (49.5\%); 289.9 & $\begin{array}{l}<0.00 I ; U=I, 827.0 \\
z=-6.194 ; r=0.29\end{array}$ \\
\hline No & 46 (92.0\%); 230.1 & & 54 (50.5\%); 229.6 & \\
\hline \multicolumn{5}{|l|}{ Ventricular tachycardia } \\
\hline Yes & 39 (2.6\%); 377.4 & $\begin{array}{l}<0.00 I ; U=864.5 \\
z=-4.266 ; r=0.20\end{array}$ & 3 I (7.I\%); 379.8 & $\begin{array}{l}<0.00 I ; U=838.5 \\
z=-7.768 ; r=0.36\end{array}$ \\
\hline No & 3,333 (97.4\%); 227.4 & & 405 (92.9\%); 227.4 & \\
\hline \multicolumn{5}{|l|}{ All six alarms compiled } \\
\hline Yes & 298 (2.6\%); 396.6 & $\begin{array}{l}<0.00 I ; U=654.0 \\
z=4.439 ; r=0.2 I\end{array}$ & | 25 (22.9\%); 309.I & $\begin{array}{l}<0.00 I ; U=1,616.5 \\
z=6.858 ; r=0.32\end{array}$ \\
\hline No & I I,047 (97.4\%); 227.0 & & $42 I$ (77.I\%); 229.1 & \\
\hline
\end{tabular}

Notes: Mann-Whitney $U$-test. Lines in bold depict statistically significant results with $P<0.005$. "Yes" = at least one alarm triggered by cardiopulmonary arrest patient in the category; 17 cardiopulmonary arrest events were experienced by II unique patients. Numerous arrhythmia alarms were triggered. Using nonparametric measurements, this table compares the number of true and false alarms in each of the six arrhythmia categories that were triggered in association with a cardiopulmonary arrest versus alarms triggered at other times. $2.4 \%$ of $\mathrm{N}=46 \mathrm{I}$. "No"= no false arrhythmia alarm triggered during cardiopulmonary arrest.

\section{Altered mental status}

Our study identified the prevalence and frequency of nuisance alarms associated with confused and agitated patients. Our work was able to identify and quantify the problem beyond anecdotal reports.

\section{Bundle branch block}

Drew et a ${ }^{24}$ recognized the concern of intensive care nurses becoming fatigued and disenchanted with cardiac monitoring technology in connection with ST monitoring more than 10 years ago (2005) and provided expert guidance for which patients to monitor and which not to monitor. The authors advised that patients with left bundle block, intermittent right $\mathrm{BBB}$, or ventricular pacing were subject to frequent false ST alarms, erroneously indicating that the ST segments were depressed or elevated, and provided a rationale for not monitoring the ST segment in these patients. While we did not specifically address ST-monitoring alarms in the study, our results support regular assessment of the need for continuous cardiac monitoring and for tailoring the monitoring parameters for patients with left and right BBBs.

\section{Mechanically ventilated patients}

Among the surprising findings of our study was the significantly greater number of false arrhythmia alarms associated with mechanically ventilated patients. While we speculate that this increase in alarms might be associated with motion artifacts, possibly due to early mobilization of patients on ventilators to aid in their recovery, we did not uncover evidence to support this supposition in our observational study. The premise deserves further investigation with a formal hypothesis.

\section{Few patients generate many false alarms}

The two patients who generated $>60 \%$ of the nonactionable arrhythmia alarms did have BBB and were mechanically ventilated. Patients whose monitors generate an abundance of 
nonactionable alarms can lead practitioners to doubt the accuracy of the signals. This mistrust can lead to patient harm. ${ }^{25}$

With only two people generating so many false alarms, a reasonable approach may be to carefully assess the need for continuous ECG monitoring in certain patients. The health care team may not find that routine assessment of the need to maintain continuous arrhythmia monitoring solves the problem, but the results may be a useful step forward in addressing the alarm fatigue issue.

\section{Signal quality}

Another approach to alarm management has focused on reducing impedance and achieving high-quality electrode conductivity to reduce the number of alarms associated with poor quality. Proper skin preparation prior to electrode placement, changing electrodes daily, or use of high-quality electrodes has been studied. Cvach et $\mathrm{al}^{26}$ concluded that instituting a daily electrode change might reduce the incidence of nuisance alarms. Although $73 \%$ of false alarms in our study were rated as having good signal quality, our findings showed that a higher proportion of false alarms, compared with true alarms, was associated with less-than-good ratings for asystole, accelerated ventricular rhythm, pause, ventricular bradycardia, and ventricular tachycardia alarms.

\section{Complex problem supports tailoring alarms for the individual}

Tailoring of patient parameter alarms, ie, adjusting high or low settings on heart rate, respiratory rate, pulse oximetry, and pressure alarms, to help alleviate the nuisance of false or nonactionable alarms, is one frequently recommended approach. ${ }^{1,20,26}$

The conclusions of the Healthcare Technology Foundation's Clinical Alarms Committee 2005-06 survey remain relevant, ${ }^{23}$ especially on recognition of the complexity of the problem, and can serve as a launching pad for moving to the next steps in alarm management. Our study has advanced the process for managing alarm fatigue described by the National Association of Clinical Nurse Specialists, ${ }^{27}$ and our findings support the premise that in critical care, universal alarm settings are not appropriate for all patients. Tailoring alarms for the individual is essential.

\section{Need for a multipronged approach to alarm management}

Management of physiological alarms to increase specificity without decreasing sensitivity requires action on numerous fronts. Standardized hospital quality improvement programs may be beneficial for decreasing incidence of unnecessary alarms. For example, Graham and $\mathrm{Cvach}^{28}$ recommended that health care personnel regularly assess alarm parameters to ensure they are set at actionable levels, participate in training to tailor alarms to the individual, and assist in establishment of standards for alarm management at the institutional level. Our study supports the premise that more than one approach may be necessary to improve the quality of alarm management and safety, especially in relation to arrhythmia alarms.

Our work has moved the science forward by describing and measuring the extent of the problem, by analyzing the data to identify patient characteristics associated with alarms, especially in relation to arrhythmia alarms, and by providing evidence to aid in designing better alarm management systems.

\section{Limitations}

We recognize the limitations of our study. First, the focus on the study was on distinguishing true versus false alarm events and not missed arrhythmia events. Missed arrhythmia events were not addressed in our study. Our research examined true or false-positive arrhythmia events only. Further study will be needed to identify false-negative alarms.

Next, our analysis indicated that other alarm states, eg, premature ventricular contractions and atrial fibrillation alarms, as well as parameter alarms such as heart or respiratory rates falling outside assigned limits, accounted for most of the alarms. Clearly, these alarms contribute to alarm fatigue, but we did not determine whether they were true or false.

Finally, the time frame for the study covered 1 month. A longer period of time may have revealed a different pattern of alarms.

\section{Future research directions}

Next steps include collecting data over a broader time frame, identifying false-negative events, determining whether or not alarms correlate with actionable events necessitating an intervention, examining additional arrhythmias - especially atrial fibrillation, and assessing parameter alarms. Closer scrutiny of the patients who generated only true alarms may also prove to be enlightening.

\section{Conclusion}

Patients likely to trigger a higher number of false arrhythmia alarms tend to be those with altered mental status, on mechanical ventilation, or who have a wide $\mathrm{QRS}$ complex due to $\mathrm{BBB}$. Only a few patients generate the majority of false alarms. Regular assessment of the need for arrhythmia monitoring and tailoring physiologic alarms to the individual patient's needs is highly recommended as a reasonable approach for 
alarm management. Thoughtfully assessing the benefit versus the risk of continuous ECG monitoring for each individual patient upon admission, in addition to reassessing regularly, may reduce the incidence of false arrhythmia alarms.

\section{Acknowledgments}

The abstract of this paper, "Patient characteristics associated with false arrhythmia alarms in intensive care" (Abstract 19717) was presented at the American Heart Association Scientific Sessions Conference, Chicago, IL, USA, in 2014. The poster's abstract was published in "Poster Abstracts" in Circulation. 2014;130:A19717 (http://circ.ahajournals.org/ content/130/Suppl 2/A19717). This study fulfills a specific aim of Analysis of Patient Monitor Alarms in Adult Intensive Care Units, research funded by GE Healthcare through a contract with University of California, San Francisco. Patricia R Harris was the project director. The funder had minimal role in study design and no role in data collection and analysis, decision to publish, or preparation of the manuscript. The authors wish to acknowledge and thank Barbara J Drew, the investigator who initiated this study, for her guidance and for the sharing of her expertise, essential for the completion of this work.

\section{Disclosure}

The authors report no conflicts of interest in this work.

\section{References}

1. Sendelbach S, Funk M. Alarm fatigue: a patient safety concern. $A A C N$ Adv Crit Care. 2013;24(4):378-386.

2. Drew BJ, Harris P, Zegre-Hemsey JK, et al. Insights into the problem of alarm fatigue with physiologic monitor devices: a comprehensive observational study of consecutive intensive care unit patients. PLoS One. 2014;9(10):e110274.

3. The Joint Commission. The Joint Commission announces 2014 National Patient Safety Goal. Jt Comm Perspect. 2013;33(7):1-3.

4. Julian DG. The history of coronary care. Br Heart J. 1987;57:497-502.

5. Morrow DA, Fang JC, Fintel DF, et al. Evolution of critical care cardiology: transformation of the cardiovascular intensive care unit and the emerging need for new medical staffing and training models: a scientific statement from the American Heart Association. Circulation. 2012;126:1408-1428.

6. Kelly FE, Fong K, Hirsch N, Nolan JP. Intensive care medicine is 60 years old: the history and future of the intensive care unit. Clin Med. 2014;14(4):376-379.

7. Breznitz S. The false alarm effect. Cry Wolf: The Psychology of False Alarms. (Chap. 2). Hillsdale, NJ: Lawrence Erlbaum Associates; 1984:9-11.

8. Simons DJ, Chabris CF. Gorillas in our midst: sustained inattentional blindness for dynamic events. Perception. 1999;28(9):1059-1074.

9. MacDonald JS, Lavie N. Visual perceptual load induces inattentional deafness. Atten Percept Psychophys. 2011;73(6):1780-1789.

10. Dehais F, Causse M, Régis N, et al, editors. Missing critical auditory alarms in aeronautics: evidence for inattentional deafness? Proceedings of the Human Factors and Ergonomics Society 56th Annual Meeting. 2012:1639-1643. Boston, MA.
11. Giraudet L, St-Louis M-E, Scannella S, Causse M. P300 event-related potential as an indicator of inattentional deafness? PLoS One. 2015; 10(2):e0118556.

12. The Joint Commission. Medical device alarm safety in hospitals. Sentinel Event Alert. 2013;50:1.

13. Weil K. Device Safety: Alarming monitor problems. Nursing. 2009;39(9):58.

14. Creighton KK, Cvach M. Monitor alarm fatigue: standardizing use of physiological monitors and decreasing nuisance alarms. Am JCrit Care. 2010;19(1):28-35.

15. Hu X, Sapo M, Nenov V, et al. Predictive combinations of monitor alarms preceding in-hospital code blue events. J Biomed Inform. 2012; 45(5):913-921.

16. Salas-Boni R, Bai Y, Harris PR, Drew BJ, Hu X. False ventricular tachycardia alarm suppression in the ICU based on the discrete wavelet transform in the ECG signal. J Electrocardiol. 2014;47(6): 775-780.

17. Bai Y, Do DH, Harris PR, et al. Integrating monitor alarms with laboratory test results to enhance patient deterioration prediction. J Biomed Inform. 2015;53:81-92.

18. Clifford GD, Silva I, Moody B, et al. The PhysioNet/computing in cardiology challenge 2015: reducing false arrhythmia alarms in the ICU. Comput Cardiol (2010). 2015;2015:273-276.

19. Bai Y, Do D, Din Q, et al. Is the sequence of SuperAlarm triggers more predictive than sequence of the currently utilized patient monitor alarms? IEEE Trans Biomed Eng. Epub 2016 Jun 30.

20. Cvach M. Monitor alarm fatigue: an integrative review. Biomed Instrum Technol. 2012;46(4):268-277.

21. Fidler R, Bond R, Finlay D, et al. Human factors approach to evaluate the user interface of physiologic monitoring. J Electrocardiol. 2015; 48(6):982-987.

22. Funk M, Clark JT, Bauld TJ, Ott JC, Coss P. Attitudes and practices related to clinical alarms. Am J Crit Care. 2014;23(33):e9-e18.

23. Korneiwicz DM, Clark T, David Y. A national online survey on the effectiveness of clinical alarms. Am J Crit Care. 2008;17(1):37-41.

24. Drew BJ, Califf RM, Funk M, et al. Practice standards for electrocardiographic monitoring in hospital settings: an American Heart Association Scientific Statement from the Councils on Cardiovascular Nursing, Clinical Cardiology, and Cardiovascular Disease in the Young: endorsed by the International Society of Computerized Electrocardiology and the American Association of Critical-Care Nurses. J Cardiovasc Nurs. 2005;20(2):76-106.

25. Pelter MM, Drew BJ [webpage on the Internet]. Harm from Alarm Fatigue. Patient Safety Network, Agency for Healthcare Research and Quality, U.S. Department of Health and Human Services; 2015. Available from: https://psnet.ahrq.gov/webmm/case/362/harm-fromalarm-fatigue. Accessed January 24, 2017.

26. Cvach MM, Biggs M, Rothwell KJ, Charles-Hudson C. Daily electrode change and effect on cardiac monitor alarms: an evidence-based practice approach. J Nurs Care Qual. 2012;28(3):265-271.

27. National Association of Clinical Nurse Specialists Alarm Fatigue Task Force. Alarm fatigue: strategies to safely manage clinical alarms and prevent alarm fatigue. Alarm Fatigue Toolkit. 2014:1-27. Available from: http://nacns.org/professional-resources/toolkits-and-reports/ alarm-fatigue-toolkit/. Accessed January 24, 2017.

28. Graham KC, Cvach M. Monitor alarm fatigue: standardizing use of physiological monitors and decreasing nuisance alarms. Am J Crit Care. 2010;19(1):28-34. 
Therapeutics and Clinical Risk Management

Dovepress

\section{Publish your work in this journal}

Therapeutics and Clinical Risk Management is an international, peerreviewed journal of clinical therapeutics and risk management, focusing on concise rapid reporting of clinical studies in all therapeutic areas, outcomes, safety, and programs for the effective, safe, and sustained use of medicines. This journal is indexed on PubMed Central, CAS,

EMBase, Scopus and the Elsevier Bibliographic databases. The manuscript management system is completely online and includes a very quick and fair peer-review system, which is all easy to use. Visit http://www.dovepress.com/testimonials.php to read real quotes from published authors.

Submit your manuscript here: http://www.dovepress.com/therapeutics-and-clinical-risk-management-journal 